DE ECONOMIST 157, NO. 3, 2009

\title{
CREDIT CRISIS AND DUTCH PENSION FUNDS: WHO BEARS THE SHOCK?
}

\author{
BY
}

\author{
CASPER VAN EWIJK*
}

In the aftermath of the credit crisis more than half of the Dutch pension funds is now officially designated as being 'underfunded'. By the first of April this year these funds had to hand in a recovery plan stating which measures they will take to ensure recovery within the coming 5 years. These recovery plans have aroused much controversy. Despite the fact that the mandatory recovery period has been extended from 3 to 5 years, painful decisions had to be made on pensions and contribution rates. While some argue that pension funds have to live up to the pensions as projected before, others argue that this would impose an irresponsible rise in cost to the younger generations in the future. This controversy has not died down yet, as there is a considerable chance that new recovery plans have to made in coming years.

This controversy is impossible to solve at this stage, as it entails the distribution of a shock that already happened. Yet, the current crisis underlines the importance of thinking about rules for distributing shocks in an ex ante sense. How would the shock have been distributed according to an optimal insurance contract? Such contract would benefit all parties involved in an ex ante sense; of course, not in an ex post sense after the shock has occurred. The lessons that can be drawn from such an optimal insurance or smoothing perspective is the key objective of this contribution.

First, this paper establishes the impact of the credit crisis on the wealth and consumption of different generations according to current pension rules. Second, it assesses this distribution by comparing it to theoretical models of optimal ris k sharing, in particular the seminal model of Merton (1969) and Samuelson (1969), and its extensions to include human capital (Bodie et al. 1992) and intergenerational risk sharing (Gordon and Varian 1988). Although these theoretical models are useful as a benchmark, they cannot be applied directly to the situation in the Netherlands. To be more specific, one of the main results of our analysis is that - compared to these benchmarks - too much burden is put on the babyboom generations while younger and future generations contribute too little. Changing this distribution is not easy, however. Under current rules in the Netherlands, pension funds

\footnotetext{
* Corresponding author: CPB Netherlands Bureau for Economic Policy Analysis, University of Amsterdam, and Netspar, Van Stolkweg 14, PO Box 80510, 2508 GM, The Hague, The Netherlands, e-mail: c.van.ewijk@cpb.nl
} 
lack sufficient instruments to realize this alternative distribution in a nondistortionary manner. If done with current instruments it would amount to a prohibitive increase in the implicit tax in pension contributions. This gap between the 'ideal' contract and the actual contract may be a matter of concern when evaluating the current pension system in the Netherlands. This paper aims to contribute some insight into the size of this gap.

\section{CREDIT CRISIS AND PENSION FUNDS}

The problems of pension funds emerged in 2008 when the stock market crash took away some 130 billions of euros, representing a quarter of all accumulated pension wealth. On top of that the balance of pension funds was further deteriorated by the fall in interest rate which raised the value of the pension entitlements by 85 billion. In this scissors movement of assets and liabilities the official funding ratio fell from a comforting $144 \%$ by the end of 2007 to no more than $90-95 \%$ in the beginning of 2009. This is well below the critical minimum rate of $105 \%$. The funding ratio measures financial wealth of pension funds relative to the 'nominal' pension liabilities. These nominal entitlements can be regarded as a minimum guarantee for participants below which their pension will not fall, except for very special circumstances. Each participant builds up nominal entitlements gradually over his of her life cycle when he or she is contributing to the pension fund. Per year each participant, for example, builds up $13 \frac{3}{4} \%$ of his or her current wage. Over a time span of 40 years this accumulates into a total pension entitlement of $70 \%$, that is 40 times $13 / 4 \%$, of the average nominal wage over the life cycle. Some pension funds in recent years have adopted higher accrual rates of around $2 \%$. What is crucial here, is that this pension accrual it is in nominal terms and thus subject to erosion due to inflation. In normal circumstances, if the funding position allows for this, pension funds adjust these nominal entitlements by indexing them to inflation or wage growth. In recent years most pension funds have introduced more or less explicit rules for this indexation, linking it to the funding ratio of the fund. For example, the largest pension fund, ABP, covering all civil servants, gives zero indexation if the funding ratio falls short of 105 and full indexation if it exceeds 135 . In between, the indexation is partial, declining linearly between 135 and 105 . Similar rules are applied by most other pension funds.

In their recovery plans pension fund must specify how they will restore their funding ratio to the minimum of $105 \%$ in the 5 years period 2009-2013. ${ }^{1}$ How this recovery is realized, which instruments are going to be used, is up to the decision of each individual pension fund. The plan is

1 This supervisory framework (Financieel Toetsingskader, FTK) is scheduled for an official evaluation next year, 2010. 
TABLE 1 - PROJECTION OF PENSION FUND RECOVERY USING STATUTORY RECOVERY PERIODS OF 5 AND 3 YEARS

\begin{tabular}{llllcrr}
\hline & 2009 & 2010 & 2011 & 2012 & 2013 & 2030 \\
\hline $\begin{array}{l}\text { Five years recovery } \\
\quad \text { Contribution rate rise }\end{array}$ & 1.0 & 0.2 & 0.2 & 0.2 & 0.2 & 0.0 \\
$\quad$ Indexation cut & 2.4 & 1.3 & 1.6 & 1.8 & 2.1 & 0.0 \\
$\quad$ Funding ratio & 100 & 104 & 107 & 110 & 114 & 141 \\
$\begin{array}{l}\text { Three years recovery } \\
\quad \text { Contribution rate }\end{array}$ & 1.0 & 2.8 & 2.8 & 0.0 & 0.0 & 0.0 \\
$\quad$ Indexation cut & 2.4 & 1.3 & 1.6 & 1.8 & 1.9 & 0.0 \\
$\quad$ Funding ratio & 100 & 105 & 109 & 112 & 116 & 142 \\
\hline
\end{tabular}

Explanation: Contribution rate and indexation cut are expressed in percentage of wages. Expected wage growth and other underlying data are taken from CPB (2009) for the period up to 2009. From 2011 onwards wage growth is taken to be $3.7 \%$, inflation $2 \%$, and the interest rate $3.5 \%$. The nominal return on the pension fund portfolio is $5 \%$ and the pension accrual rate $2 \%$. Projections on aggregate pension funds are based on calculations by $\mathrm{CPB}$ using data on all pension funds.

evaluated by the supervisor, The Netherlands Bank, on its consistency, using certain maximum values for interest rates and asset returns. In the current plans there is a general tendency to emphasise cuts in indexation rather than rises in contribution rates. One reason for this is that contribution rates are already high after the stock market fall in 2002. A second reason is that cutting indexation is far more effective than raising contribution rates. A third reason may be that pension funds are reluctant to increase contribution rates during a recession. Thanks to the decision of the Minister of Social Affairs to extend the statutory recovery period temporarily from 3 years - as it was originally put in legislation - to 5 years, no pension fund so far had to decide to absolute cuts in pensions in nominal terms. According to the pension law such direct cutting of entitlements is allowed only in special circumstances, if other solutions fail.

Table 1 provides an projection for the recovery of aggregate pension funds in the Netherlands up to 2030. It shows that only a moderate increase in contribution rates (measured in percentage points of wages) is necessary to achieve recovery of the funding ratio up to 105 by the end of 2013. Most of the work is being done by the cuts in indexation. By foregoing indexation, pension funds save an increase in liabilities equal to nominal wage growth. In 2009, for example, this amounts to $2.4 \%$ of the wage sum. For following years savings are smaller as wage growth is expected to fall due to the recession. When full indexation is restored again (as late as 2030) the savings are 


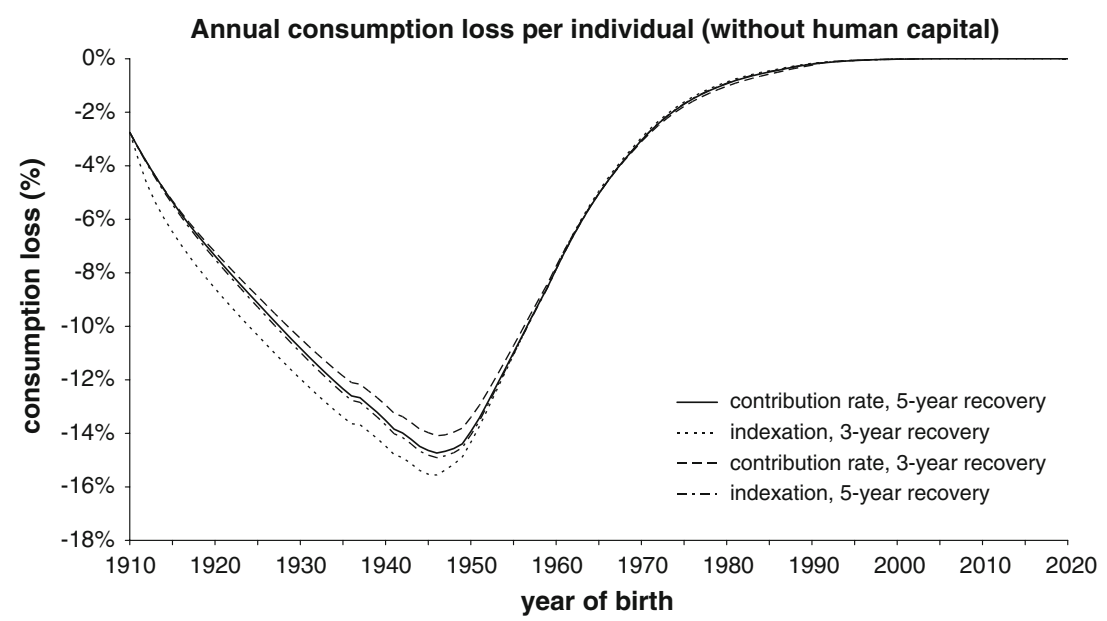

Figure 1 - Generational effects of the pension shock: percentage loss in life time consumption per cohort by year of birth

zero. These calculations are based on a linear indexation rule going from 0 to $100 \%$ for funding ratios from 105 to 140 .

If the government would have stuck to the original recovery period the problems of pension funds would have been far more acute. The second panel in Table 1 reveals that contribution rates would then have needed to increase by $2.8 \%$ in 2010 and 2011. Such an increase is generally regarded as being out of the question in practice. Therefore a cut in nominal pensions would have been inevitable for some pension funds at least. In effect, by extending the recovery period from 3 to 5 years the Dutch government has postponed a decision on the option of directly cutting nominal pension entitlements. It should be noted that all projections in Table 1 are subject to considerable uncertainty (see Rooij et al. 2008 for a stochastic analysis). In more optimistic scenario with a portfolio return of $8 \%$ rather than $5 \%$ (roughly one standard deviation higher) no rise in contribution rate would be needed at all. However, a return of $1 \%$ (one standard deviation lower) would require absurd rises in contribution rates of more than $7 \%$ points on average over the 5 years recovery period.

\section{BABYBOOMERS HURT MOST}

How the losses of pension funds are distributed over their beneficiaries can be established using generation accounts (Auerbach et al. 1991). The loss for each cohort comprises both lower pension payments and higher contribution rates, measured over its remaining lifecycle. Figure 1 gives the loss for each 
cohort — by date of birth - expressed as a percentage of life time consumption. Clearly, older workers and just retired generations lose most, ranging up to $15 \%$ for the cohorts born just after the World War II. The old generations who are already retired for some time are less affected as pension funds stretch their recovery of their funding over a longer time period. In particular, the system of cutting indexation has only a gradual, cumulative effect over time. The younger generations, say born after 1970, suffer only little. They have built up very little entitlements so far, and they benefit most from the period after pension funds have recovered. Future generations, say born after 1990, participate hardly at all in this shock, indicating that second pillar schemes in the Netherlands hardly contribute to risk sharing with future generations, at least for the current schock.

The distributional effects are quite insensitive to changes in pension fund policies. Figure 1 also shows the impact of two alternative policies: one with a shorter, 3 years, recovery period (intermitted line), and a second variant with fixed contribution rate. In the latter case all emphasis is put on cutting indexation, including - if necessary - the possibility of cutting entitlements, which is not necessary at current parameters. The first alternative features stronger contribution rate raises, and thus shifts the burden more to the younger generations, offering some relief to the older generations. The effect is small though, less than $1 \%$ point for the babyboomers who lose up to $15 \%$ in total. In contrast, the second alternative puts more of the burden to the elderly by cutting their entitlements. Again this has only a minor impact in these projections. This may be different in more pessimistic scenarios where cutting entitlements may hurt the elderly harder.

\section{REDISTRIBUTIVE IMPACT OF THE PENSION SYSTEM}

A key function of the pension system is to smooth risks among cohorts of different ages. It is well established that intergenerational risk sharing can generate substantial welfare gains (Gollier 2008, Van Ewijk et al. 2009). The above results on Dutch pension funds are not very reassuring in this respect. On the contrary, the current pension system in the Netherlands turns out to put most of the financial risks on the shoulders of the older workers and retirees. One could even doubt if there is any redistribution in the right direction - that is, from old to young - at all. Although this question is simply put, the answer is not easy to obtain. To assess the redistributive characteristics of the current pension system one needs a benchmark to compare actual results with. One such a benchmark could be the standard textbook case of optimal private saving and portfolio investment as developed by Merton (1969) and Samuelson (1969). This model has the neat implication that-under constant relative risk aversion (CRRA) - the desired risk exposure to shocks is constant all over the life cycle. To put it differently, all cohorts feature the 


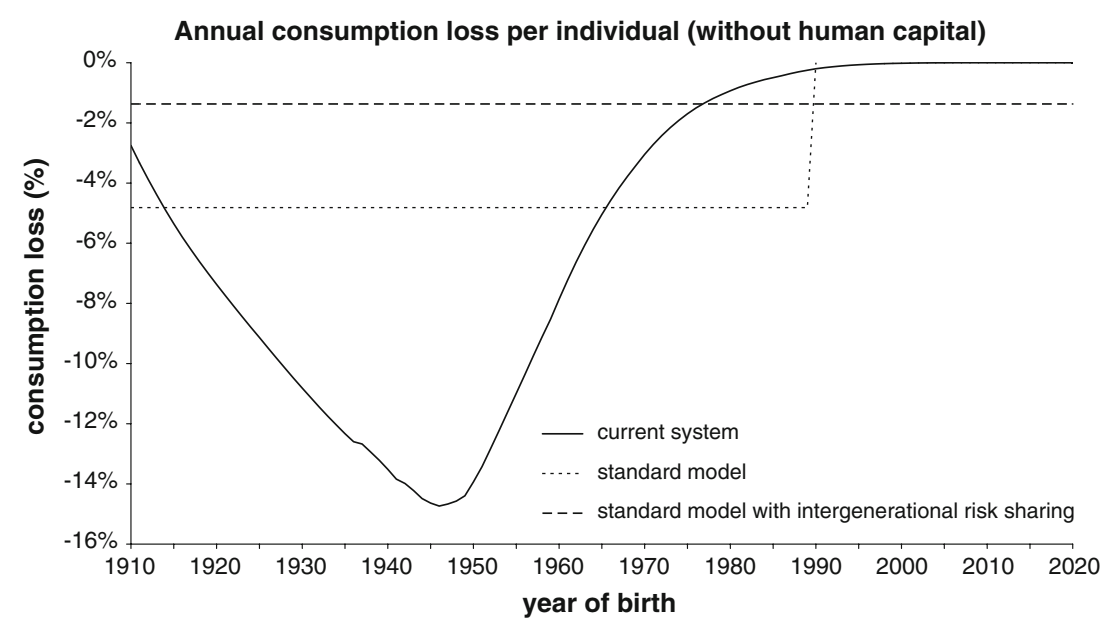

Figure 2 - Generational effects of the pension shock relative to the theoretical standard model

same exposure to a certain risk, independent of their age. As a result shocks have to smoothed over all generations in proportion to their wealth (see also Bovenberg et al. 2007). Applying this to the pension shock, one would expect a flat distribution in percentage of consumption over all cohorts. This alternative distribution is shown in Figure 2, together with the initial V shaped distribution. The dotted curve represents the distribution according to the standard theoretical model where the shock is perfectly smoothed over all current generations participating in the pension fund. In this case, each cohort would lose $4.8 \%$ of consumption over the rest of their lifetime. Smoothing can even be extended over all future generations as well (Gordon and Varian 1988). Then the average loss per cohort would fall to $1.4 \%$. This latter case represents the case of perfect intergenerational risk sharing.

Taking the first alternative as a benchmark it can easily be seen that relative to this standard model the current pension contract puts too much burden on all retirees - the few being born before 1914 excepted-and working generations born before 1965. Cohorts born after 1965 contribute too little to the shock according to this benchmark. In case of perfect intergenerational smoothing, where also future generations are involved, all generations born before 1976 give up too much consumption, while all younger and future generations contribute too little. The effects are not negligible. For example the babyboomers, who have to sacrifice consumption by $15 \%$ under the current system, would lose only $4.8 \%$ in the standard model with perfect smoothing among current generations, a difference of almost $10 \%$. In case of intergenerational smoothing this difference would further increase to over $13 \%$. This suggest that risk sharing under the current system is far from optimal; there is scope for substantial improvement. 
Can we conclude that the pension system on balance redistributes risks in the wrong direction? That is from the young to old rather than vice versa? This might be true, indeed, if we can consider the benchmark of perfect smoothing as a more or less realistic description of individual behaviour in the absence of pension funds. This is unfortunately not very likely, for a number of reasons. For the case of perfect intergenerational risk sharing is obviously too extreme as markets for trading with future generations are lacking. But also the more restrictive benchmark of perfect smoothing among current generations is rather optimistic. First, preferences may deviate from standard time separable CRRA utility. For example in case of habit formation-for which there is empirical support - one would put less risks on elderly. This would make the case for shifting more of the burden to younger generations, who have more time to accommodate to the shock, even stronger.

Second, and more important, market imperfections prevent individuals from picking their ideal saving and investment profile. For example, the short selling constraint precludes young agents to take a long position in stock and going short in bonds, as is implied in the Merton Samuelson model. Compared to a more realistic representation of hypothetical free market portfolios, the Dutch pension system is therefore probably less perverse than may seem at first sight when it is compared to the theoretical benchmarks. Unfortunately, we are not able to make any reliable statement on what the household portfolio would have been in the absence of the pension system. In the absence of a clear cut and realistic benchmark, the question on the real contribution of pension funds to risk sharing has to remain unanswered at this stage. $^{2}$

\section{HUMAN CAPITAL SHOCK}

One factor is forgotten so far. The foregoing focused on financial risk only. The credit crisis, however, affects generations in a number of other ways as well. One obvious factor is human capital. Although it is highly uncertain what the impact of the credit crisis is going to be over a longer horizon, it no wild guess if we assume that there will be a prolonged effect on economic growth, and therefore on wages and employment. On the basis of historic analysis of previous financial crises Reinhart and Rogoff (2009) estimate GDP on average falls with $9 \%$ from peak to through. Unemployment can rise

2 In more practical terms one could determine the redistributive effect by comparing the actual loss with the benchmark in which total loss is distributed in proportion to the nominal entitlements of participants. In that case just the opposite picture emerges, with the young being net contributors that reduce the losses to the old (see Boeijen et al. [2009] for a similar approach). This approach is problematic, however, as there is no reasonable underpinning for using the nominal entitlements as a benchmark for a 'neutral' distribution. 


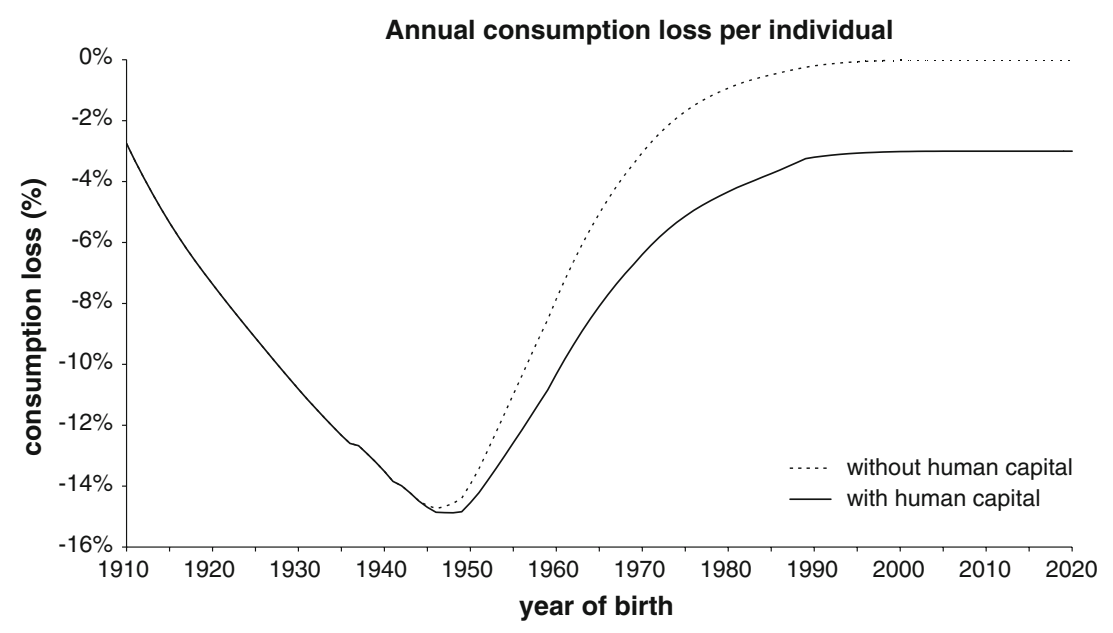

Figure 3 - Generational effects of the pension shock including human capital

with 7\%. How this affects long term economic growth is hard to tell. Unemployment rises over a period of 7 years according to Reinhart and Rogoff . The decline in GDP takes only 2 years on average, where after recovery follows. Taking a loss in output of $10 \%$ relative to trend after 2 years $(9 \%$ plus trend growth of $4 \%$ over 2 years minus the initial output gap of $3 \%$ ), declining to $7 \%$ after 7 years and thereafter steadily declining, the loss in human capital over an average time horizon 25 years, is found to be about $3 \%$. For older workers the loss will be somewhat bigger, as they are hurt most by the loss in wages and unemployment which are strongest in the first years after the crisis. Younger workers will be hurt less in relative terms, as they still have a long future to go. On the other hand, it seems plausible that the incidence of unemployment is stronger for the younger generations. The average loss of 3\% is determined using a given discount rate (3\% in real terms). There is one important proviso: if the risk premium for human capital is increased by the crisis, similarly to equities, the drop in human capital could be significantly higher. Increasing the discount rate by $1 \%$ point (from 3 to $4 \%$ ) can easily increase the loss in human capital to more than $13 \%$. This again underrates the enormous uncertainty underlying these projections.

In our calculations, as presented in Figure 3, we neglect the differential impact on generations and take a uniform loss of 3\% of their human wealth for all cohorts. Since this loss of 3\% is considerably smaller than the loss in pension wealth, which ranges up to $15 \%$ of consumption, we can expect that including the shock in human capital mitigates the skewness in the distribution, but does not take it away completely. This is illustrated in the figure. For all retired generations there is no change; for the working gener- 


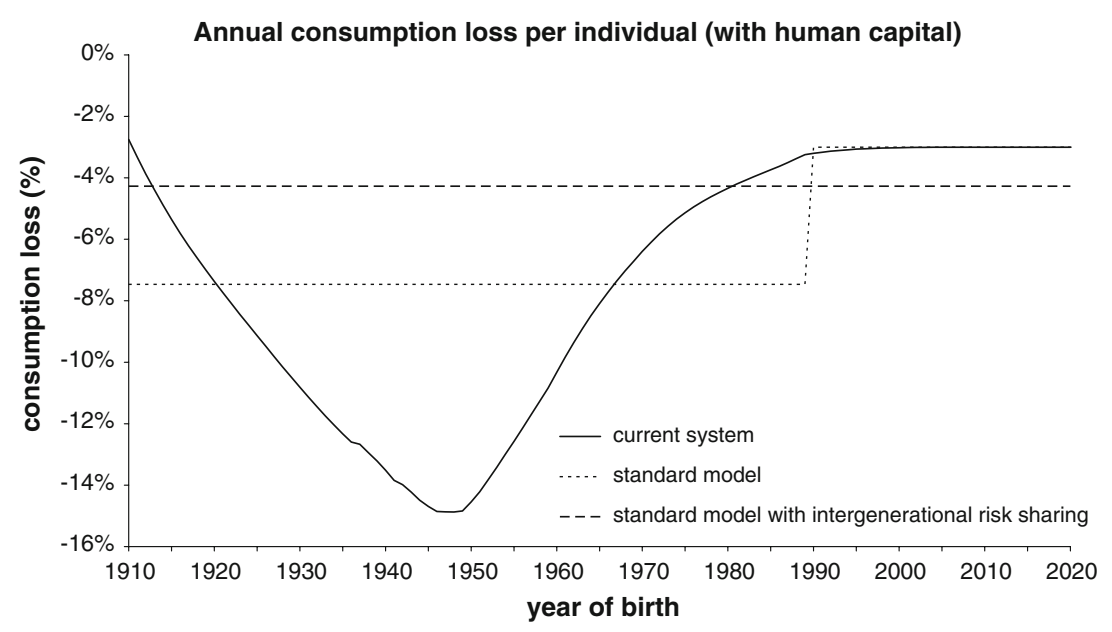

Figure 4 - Generational effects of the pension shock relative to the standard model including human capital

ations and future generations the loss increases in proportion to their human wealth, which based on actual wage and participation profiles for the Netherlands (Ewijk et al. 2006).

The inclusion of human capital reduces the scope for risk sharing with younger generations. Figure 4 reveals that the loss would amount to 7.5 for all cohorts in the standard model with perfect smoothing among current generations. This is higher than the $4.8 \%$ found for the similar case without human capital. Even at this higher rate there is still substantial scope for redistribution. Generations born around 1945 would in this case gain $7.5 \%$ by perfect smoothing. When the actual outcomes are compared to the benchmark of perfect intergenerational risk sharing, where all generations including future generations would give up $4.3 \%$ of consumption, this would imply a gain of $10 \%$ for the babyboom generations. The overall conclusion that there is scope for further redistribution among older and younger generations remains valid.

Even after the inclusion of the shock in human capital this approach still remains partial. There are many other channels through which the credit crisis affects the intergenerational distribution. One important mechanism concerns the housing market. A decline in housing prices means a loss to older generations, who on average have larger housing wealth. In contrast, younger generations gain by the lower house prices, as they can buy the current housing stock cheaper. Second, households are also affected by losses on their financial portfolios. Again, this probably hurts older generations more than the young generations, as they have accumulated more capital. 
A third important channel concerns the net benefit of government revenues and expenditures. This has been taken as given in our analysis. This is not fully accurate. For example, public pensions can also be expected to decrease following the decrease in wages. On the other hand also other transfers will fall as well, for example student loans or social assistance, which are more important to younger generations. Furthermore, the government can decide to smooth the shock more or less to future generations through debt policy. Such an encompassing analysis of the generational impact of the credit crisis is beyond the scope of this article. At first sight, it seems not likely that these other channels would change the purport of our analysis. The impact through the government budget will not overhaul the direct effects of the shock through pensions and human capital (see also Ewijk et al. 2006). And the fall in housing prices and private financial portfolios can be expect to aggravate the skewness of the distribution rather than mitigate it as it hurts the babyboomers in particular.

\section{LACK OF INSTRUMENTS AND LABOUR MARKET DISTORTION}

The pension system in the Netherlands allows for only a few instruments to be used by pension funds. This sets serious limits on the redistributive capabilities of pension funds. In particular, in normal circumstances, it is not allowed to cut entitlements directly in case of losses, or add to these entitlements in case of gains. The principal instruments are the indexation of entitlements and the level of contribution rates. In company pension funds the sponsor can participate in losses and gains by transfers to or from the fund. In the aggregate this plays only a minor role in the Netherlands as most important pension funds are sectoral funds which have no immediate sponsors they can revert to when needed. Indexation and contribution rates are moreover commonly applied in a uniform manner, that is, using the same rates for every cohort. This follows from the history of pensions as collective arrangements in which solidarity was of paramount importance. This limited room of maneuver for pension funds has recently endorsed in legislation in the Pension Law of 2006. Uniform contribution rates together with uniform indexation makes it impossible for pension funds to tailor the distribution of shocks to a desired distribution. ${ }^{3}$

Figure 1 already revealed how little alternative policies affect the overall distribution. There are two basic problems regarding the effectiveness of pen-

3 In theory time specific taxes may be sufficient to obtain any distribution as desired (Calvo and Obstfeld 1988). This not true in this case, however, as there are additional restrictions, one on the time path of funding ratio due to the legal recovery period, and another on effectiveness of the indexation instrument which has a maximum equal to nominal wage growth, as the indexation cut can never exceed $100 \%$ of wage growth. This latter restriction implies that it there is a limit to the burden that can be put on older generations. 
sion fund instruments: First, pension funds lack cohort specific instruments as long as they are tied to uniform contribution and indexation rules. Second, and even more important, indexation and contributions cause labour market distortions as they both affect the price of pensions in an ex ante sense. That is, they put an implicit tax on labour of the participants. This puts a serious limit to how much losses and gains can be recouped in a certain time span. Too high contribution rates are impossible, certainly in this time of economic recession, as it would further distort the labour market, and thereby aggravate the crisis. The same holds for the indexation, as this similarly raises the implicit tax in pension contributions. Lower indexation means that participants receive less pension for a given contribution. Also, the alternative of lowering the pension accrual rate (currently about $13 / 4$ to $2 \%$ ) suffers from this same problem that it distorts the labour market.

The magnitude of the implicit tax can be illustrated considering for example the cohort aged 20 at this moment (born in 1989). Figure 3 shows that this cohort would have to pay an additional $4 \%$ on a life time basis if pension funds implement perfect smoothing among current generations. If this is done by current instruments this would yield an implicit tax of at least $4 \%$ over the life cycle of this cohort. This additional implicit tax comes on top of the implicit tax that is in the baseline for recovery already, which amounts to $1.4 \%$ on average during the first 10 years. $^{4}$

How can this smoothing alternative be approximated using existing instruments of pension funds? The burden can be shifted from the old to the young by putting more emphasis on higher contribution rates and less on cutting indexation of pensions. By way of alternative, consider the case in which indexation cuts are halved relative to original projection in Table 1 (upper panel). To attain the same speed of recovery over 10 years, contributions have to be raised by an additional $5 \%$ during this entire period. Figure 5 reveals that this alternative scenario shifts the burden more to the young, indeed. The loss of the babyboom generations falls from 15 per cent to $7 \frac{1}{2}, \%$, just similar to the loss in case of perfect smoothing among current generations. However, for other generations the match is still far from perfect. Now generations born around 1960 are worst off, losing some 10\% in consumption terms. Two other groups are still shielded to the shock. Both the oldest generations (born before 1945) and the younger generations (born after 1970) contribute too little relative to the smoothing alternative. It is difficult to tailor the distribution more precise to these groups.

What is worse, however, is that this alternative implies huge implicit tax rates in pension contributions. For the younger cohorts pension contributions

4 This neglects any distortion already contained the basic premium. Bonenkamp [2009] shows the system of uniform contribution rate entails an implicit tax for the younger cohorts of about $3 \%$. If this is taken into account too, the implicit tax would even be higher. 


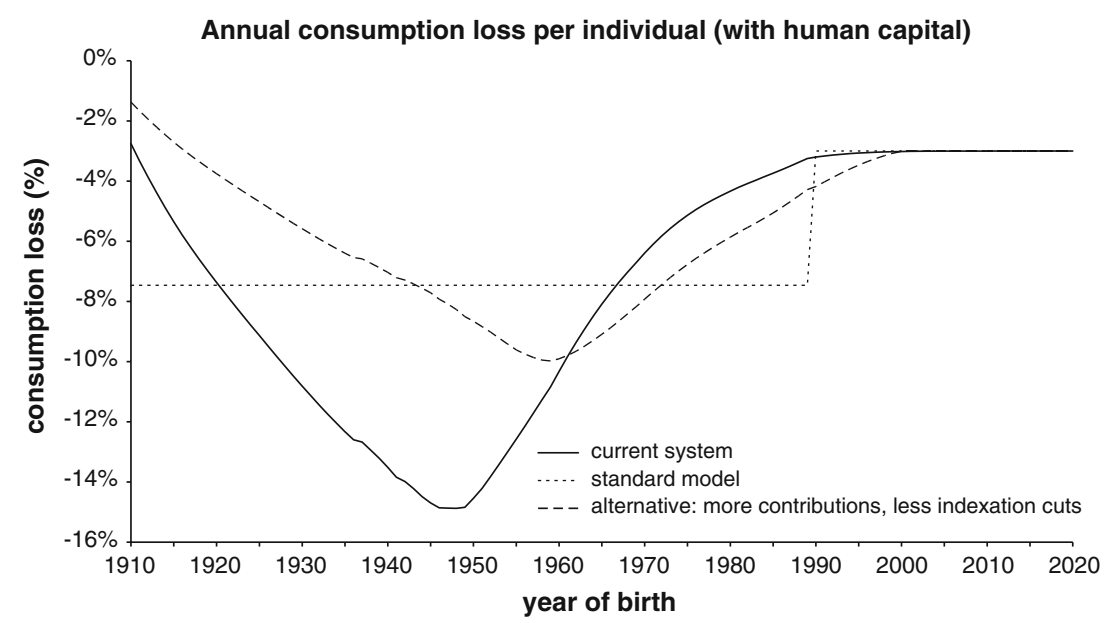

Figure 5-Generational effects of a approximate smoothing alternative using current instruments

would involve an additional implicit tax of about $5 \%$ on top of the $1.4 \%$ already contained in the baseline projection. Given the already high tax rates in the Netherlands such a tax rate is generally seen as prohibitive.

High implicit tax rate on pensions may also threaten the very continuity of the pension system. If the distance between what (young) participants pay and what they get in return as pension value becomes too large, this will make participation in the pension fund unattractive to new participants. Although the pensions are mandatory for workers in a sector, people can decide to become self-employment rather than employee. Furthermore, there is some scope for companies not to join the pension fund of their sector. Such avoidance of participation would erode the pension system from the inside.

The implicit tax could be reduced it the smoothing is extended over all future generations as well. This would save about $3 \%$ in tax increase (see Figure 4). This is a substantial relief. Unfortunately it requires a strong commitment of all future generations. It would imply that all future participants would contribute a solidarity tax of more than $1 \%$ over an indefinite time horizon.

\section{DISCUSSION}

The credit crisis has caused unprecedented losses to Dutch pension funds. This exceptional situation puts the pension contract as it has evolved in recent years to test. The positive news is that - thanks to the extended reg- 
ulatory recovery period-pension funds can accommodate the shock using the standard policies of adjusting contribution rates and indexation. The bad news is, however, that the distributional effects of such policies are highly skewed. The older generations, in particular the cohorts born just after World War II, are hurt excessively by the shock of the crisis, losing up to almost $15 \%$ of consumption during their remaining life time. This contrasts with the younger generations who loose hardly any pension wealth. Even if one takes into account that younger generations are hit in their human capital-here taken at 3\% on a life time basis - this does not balance with the losses of the older generations. Using these data, there is scope for stronger redistribution in the Dutch pension system than is captured in the current pension contract.

There are some major uncertainties, however. First, the loss in human capital is hard to determine; not only is the impact of the credit crisis on future wages and employment uncertain, but also - and in quantitative terms more important -the value of human capital is very sensitive to the risk premium. If this risk premium has gone up by the credit crisis - which is not unlikelythis could lead to a much more drastic fall in human capital. Second, this analysis, although it focuses on two key mechanisms, is partial in the sense that it neglects the intergenerational effects of the credit crisis through the housing market, private financial wealth, and last but not least the government budget.

It is not a matter of distributive impact of pensions only. The pension contract itself is at stake. Under the current regulatory rules pension funds are unable to shift more of the burden to younger generations without causing great welfare losses on the labour market. Each of the instruments of pension funds require that losses are recouped by putting an implicit "solidarity" tax on labour during the recovery. Stronger redistribution is therefore only possible if the current pension contract is redesigned. In particular, what is needed is an instrument that can impose losses on participants by a-non distortionary-adjustment in pension entitlements rather than levying a implicit tax on all future contributions.

Would such an alternative contract solve all problems in the second pension pillar? No, even with improved instruments the pension system will face restrictions. In particular, it will hard to organize risk sharing with future generations that have not yet entered the pension system. Such risk sharing would imply that new participants may have bad luck, and start with a negative initial wealth when entering the pension fund. Such a negative position arises if there have been a series of negative shocks in the years before this generation enters. It is far from evident that these new generations would accept such a starting point. If this initial loss becomes too large, the continuity of the fund may still be at risk. 
So, while allowing for new instruments may solve the distortionary impact on the labour market, it does not take away the risk of the discontinuity for the pension fund. Similarly, one may doubt if participants who have just entered to pension fund will accept the consequence of full smoothing among the participants. This would in effect imply a very high risk exposure for the youngest generation in their pension wealth, which can easily lead to a substantial negative position. So even for current participants optimal smoothing requires a lot from the credibility of the pension contract, and thus of the commitment of pension funds. Under the current system which is based on essentially implicit contracts there is certainly still a long way to go. Along this route, making contracts explicit can be regarded as a first prerequisite to improve the scope for efficient risk sharing. This would strengthen the basis for risk sharing, at least among current generations of participants. For risk sharing with future generations, one could doubt whether pension funds are really geared to this task. In the end, the government may be better able to commit future generations than pension funds.

\section{ACKNOWLEDGMENTS}

Help with the simulations by Jan Bonenkamp and comments on the text by Lans Bovenberg and Ed Westerhout are gratefully acknowledged.

Open Access This article is distributed under the terms of the Creative Commons Attribution Noncommercial License which permits any noncommercial use, distribution, and reproduction in any medium, provided the original author(s) and source are credited.

\section{REFERENCES}

Auerbach, A.J., J. Gokhale and L.J. Kotlikoff (1991), 'Generational Accounts: A Meaningful Alternative to Deficit Accounting,' in D. Bradford (ed.), Tax Policy and the Economy, 5, Cambridge, MA, MIT Press, pp. 55-110.

Bodie, Z., R. Merton, and W. Samuelson (1992), 'Labor Supply Flexibility and Portfolio Choice in a Life-Cycle Model,' Journal of Economic Dynamics and Control, 16, 427-449.

Boeijen, D., P. Janssen, en N. Kortleve, (2009), 'Reactie op: Herstel in dekkingsgraad vergt forse pensioenoffers,' Economisch Statistische Berichten, 94, 252-253

Bonenkamp, J. (2009), Measuring Lifetime Redistribution in Dutch Occupational Pensions Jan Bonenkamp, De Economist, forthcoming.

Bovenberg, A.L., R. Koijen, T.E. Nijman and C. Teulings (2007), 'Saving and Investing over the Life Cycle and the role of Collective Pension Funds,' De Economist, 155, 347-415

Calvo, G.A. and M. Obstfeld (1988), 'Optimal Time-Consistent Fiscal Policy with Finite Lifetimes,' Econometrica, 56, 411-432. 
Ewijk, C. van, N. Draper, H. ter Rele and E. Westerhout (2006), Ageing and the Sustain Ability of Dutch Public Finances, CPB, The Hague.

Ewijk, C. van, P. Janssen, N. Kortleve and E. Westerhout (2009), Naar een reëel kader voor pensioenfondsen, NEA Paper 16, Netspar, Tilburg.

Gollier, Christian (2008). 'Intergenerational Risk-sharing and Risk-taking of a Pension Fund,' Journal of Public Economics, 92, 1463-1485.

Gordon, Roger H., and Hal R. Varian (1988), 'Intergenerational Risk Sharing,' Journal of Public Economics, 37, 185-202.

Merton, R.C. (1969), 'Lifetime Portfolio Selection under Uncertainty: The Continuous-Time case', Review of Economics and Statistics, 51, 247-257.

Reinhart, C. and K. Rogoff (2009), 'The Aftermath of Financial Crises', American Economic Review, 99, 466-472.

Rooij, M. van, A. Siegmann and P. Vlaar (2008). 'Market Valuation, Pension Fund Policy and Contribution Volatility,' De Economist, 156, 73-93.

Samuelson, P.A. (1969), 'Lifetime Portfolio Selection by Dynamic Stochastic Programming', Review of Economics and Statistics, 51, 239-246. 